\title{
Miscellany
}

\section{Amendments to the Membership List}

The following members were omitted in error from the Membership List 1998

Bird Michelle Charlotte Carol (M, 300) Retired Consultant Psychiatrist

Dennehy Constance Marguerita (F, 4167) Consultant Psychiatrist, 14 Devonshire Place, London W1N 1PB (Tel: 0171935 0640);

18 Montpellier Grove, London NW5 2XD

(Tel: 0171485 4210)

Fellowes Janet Lindsay (M, 6892)

Wig Narendra N (HF, 8460)

Professor of Psychiatry, 279 Sector 6, Panchkula (Haryana) 134 109, India (Tel: 172564 224)

\section{New publications}

Community Care Tragedies: A Practice Guide to Mental Health Inquiries by Margaret Reith is a new book published by Venture Press. Containing practical lessons in risk assessment for professionals working in mental health and criminal justice, the book will be helpful to mental health practitioners, planners, policymakers and students. Copies may be obtained, for $£ 11.50$ plus postage and package, from Venture Press, 16 Kent Street, Birmingham B5 6RD (Telephone: 0121622 3911, Fax: 0121622 4860).

Age Concern Books have recently published Reminiscence and Recall by Faith Gibson. The book aims to give tools and techniques to professionals working with older people. It can help older people recall their own history and better understand their current circumstances, and will assist carers who may be working closely with people whom in some cases they may hardly know. Available for $£ 11.99$ (freepost) from The Mail Order Department. Age Concern England, Astral House, 1268 London Road, London SW16 4ER (Telephone: 0181765 7203/8).

The Nuffield Council on Bioethics have published a report entitled Mental Disorders and Genetics: The Ethical Context. It is their belief that special safeguards must be implemented to protect people with mental disorders from genetic testing that would not be beneficial to that person. In this report, the ethical implications arising from genetic research and how the research is applied are reviewed on the basis of the fundamental need to preserve human respect and human dignity. The report can be obtained for $\$ 20$, including postage and package within Europe, from the Nuffield Council on Bioethics, 28 Bedford Square, London WC1B 3EG (Telephone: 0171631 0566, Fax: 0171323 4877).

Competence in Care is a new open learning course for anyone working with people with a learning disability. Published by Pavilion Publishing and the Association for Residential Care (ARC), this distance learning course was developed by member organisations of ARC and has three broad aims: to provide a basic set of values and attitudes, to develop competence and to relate the National Occupational Standards in Care. Priced at $\$ 95$ plus postage and package, copies may be obtained from Pavilion Publishing (Brighton) Limited, FREEPOST (BR458), 8 St George's Place, Brighton, East Sussex BN1 4ZZ (Telephone: 01273623222 , Fax: 01273625 526). 